\title{
ON COEFFICIENT FUNCTIONALS ASSOCIATED WITH THE ZALCMAN CONJECTURE
}

\author{
SARITA Agrawal and Swadesh Kumar SAHOO
}

\begin{abstract}
For a function $f$ which is analytic and univalent in the unit disk $\{z \in \mathbb{C}:|z|<1\}$ having the power series expansion of the normalized form $z+\sum_{n=2}^{\infty} a_{n} z^{n}$, Zalcman conjectured that $\left|a_{n}^{2}-a_{2 n-1}\right| \leqslant(n-1)^{2}, n=2,3, \ldots$ In this article, we obtain the sharp estimate for the classical Zalcman coefficient functional $a_{n}^{2}-a_{2 n-1}$ for the above class of functions with the restriction that the $n$-th coefficient, $a_{n}$, has certain integral representation associated with probability measure. Moreover, we also study a similar problem for the classes of functions of the above form whose coefficients satisfy certain inequalities.
\end{abstract}

Mathematics subject classification (2010): Primary 30C45, 30C55, Secondary 30C50.

Keywords and phrases: Convex functions, convex hull, probability measure, univalent functions, coefficient functional, Zalcman's conjecture.

\section{REFERENCES}

[1] Y. Abu Muhanna, L. Li, And S. Ponnus amy, Extremal problems on the class of convex functions of order -1/2, Arch. Math. (Basel) 103 (6) (2014), 461-471.

[2] O. P. Ahuja AND H. Silverman, A survey on spiral-like and related function classes, Math. Cronicle 20 (1991), 39-66.

[3] L. DE BRAnges, A proof of the Bieberbach conjecture, Acta Math. 154 (1-2) (1985), 137-152.

[4] J. E. BROWn AND A. TsAO, On the Zalcman conjecture for starlike and typically real functions, Math. Z. 191 (3) (1986), 467-474.

[5] P. L. Duren, Univalent Functions, Springer-Verlag, New York, 1983.

[6] I. EFRAIMIDis AND D. VuKotić, Applications of Livingston-type inequalities to the generalized Zalcman functional, Math. Nachr., doi:10.1002/mana.201700022, 1-12.

[7] A. W. Goodman, On uniformly starlike functions, J. Math. Anal. Appl. 155 (1991), 364-370.

[8] A. W. Goodman, On uniformly convex functions, Ann. Polon. Math. 56 (1) (1991), 87-92.

[9] J. A. Kim And N. E. Cho, Properties of convolutions for hypergeometric series with univalent functions, Adv. Difference Equ. 2013, 2013:101, 1-11.

[10] S. L. Krushral, Univalent functions and holomorphic motions, J. Anal. Math. 66 (1995), 253-275.

[11] S. L. Krushral, Proof of the Zalcman conjecture for initial coefficients, Georgian Math. J. 17 (4) (2010), 663-681. (Erratum in Georgian Math. J., 19 (4) (2012), 777.)

[12] O. S. KWON AND S. OWA, THE SUBORDINATION THEOREM FOR $\lambda$-SPIRALLIKE FUNCTIONS OF ORDER $\alpha$, Int. J. Appl. Math. 11(2) (2002), 113-119.

[13] L. Li AND S. Ponnus Amy, Generalized Zalcman conjecture for convex functions of order $-1 / 2$, J. Analysis 22 (2014), 77-87.

[14] L. Li And S. Ponnusamy, On the generalized Zalcman functional $\lambda a_{n}^{2}-a_{2 n-1}$ in the close-toconvex family, Proc. Amer. Math. Soc. 145 (2017), 833-846.

[15] L. Li AND S. Ponnus AMy AND J. QIAO, Generalized Zalcman conjecture for convex functions of order $\alpha$, Acta. Math. Hungar. 150 (1) (2016), 234-246.

[16] R. J. LiberA, Univalent $\alpha$-spiral functions, Canad. J. Math. 19 (1967), 449-456.

[17] W. MA, The Zalcman conjecture for close-to-convex functions, Proc. Amer. Math. Soc. 104 (3) (1988), $741-744$. 
[18] W. MA, Generalized Zalcman conjecture for starlike and typically real functions, J. Math. Anal. Appl. 234 (1) (1999), 328-339.

[19] M. L. Morga And O. P. Ahuja, On spiral-like functions of order $\alpha$ and type $\beta$, Yokohama Math. J. 29 (2) (1981), 145-156.

[20] CH. Pommerenke, Univalent Functions, Vandenhoeck \& Ruprecht, Göttingen, 1975.

[21] S. Ponnus Amy AND K.-J. Wirths, On the problem of Gromova and Vasil'ev on integral means, and Yamashita's conjecture for spirallike functions, Ann. Acad. Sci. Fenn. Math. 39 (2014), 721-731.

[22] V. RAVICHANDRAn AND S. VERma, Generalized Zalcman conjecture for some classes of analytic functions, J. Math. Anal. Appl. 450 (2017), 592-605.

[23] H. Silverman, Partial sums of starlike and convex functions, J. Math. Anal. Appl. 209 (1997), 221227. 